\title{
A influência de ritmos musicais sobre a percepção dos estados subjetivos de pacientes adultos em hemodiálise
}

\author{
THE INFLUENCE OF MUSICAL RHYTHMS ON THE PERCEPTION OF SUBJECTIVE \\ STATES OF ADULT PATIENTS ON DIALYSIS
}

\author{
LA INFLUENCIA DE RITMOS MUSICALES SOBRE LA PERCEPCIÓN DE LOS ESTADOS \\ SUBJETIVOS DE PACIENTES ADULTOS EN HEMODIÁLISIS
}

Leandro Bechert Caminha1 ${ }^{1}$, Maria Júlia Paes da Silva², Eliseth Ribeiro Leão ${ }^{3}$

\section{RESUMO}

Submeter-se à Hemodiálise quatro horas por dia, três vezes por semana, pode configurarse uma experiência carregada de tédio, além de causar desconforto durante sua realização. É comum os pacientes relatarem que 0 tempo parece se arrastar ou durar mais. 0 objetivo deste estudo foi conhecer a influência de dois diferentes ritmos musicais nos estados subjetivos e na percepção temposensorial de pacientes adultos submetidos à hemodiálise, uma vez que a literatura sobre essa temática é escassa. 0 estudo foi realizado em um hospital privado, com 43 pacientes em hemodiálise, que se submeteram a duas sessões de improvisação musical em um teclado, nas quais os estados subjetivos e a percepção temporal foram avaliados pré e pós-intervenção. Mais de $80 \%$ dos pacientes sentiu o tempo passar mais rápido após as intervenções em ambos os ritmos. No entanto, o ritmo influenciou o tipo de experiência emocional que os pacientes apresentaram.

\section{DESCRITORES}

Terapias complementares.

Diálise renal.

Musicoterapia.

\begin{abstract}
Being submitted to dialysis four hours a day, three times a week can mean experiencing boredom, besides discomfort. Patients often report that the time seems to take longer to go by. The purpose of this study was to explore the influence of two different musical rhythms in the states of mind and perception of adult patients undergoing dialysis, since the literature on this subject is scarce. The study was performed at a private hospital with 43 patients, who participated in two sessions of musical improvisation with a keyboard. The subjective states and perception were evaluated before and after the intervention. Over $80 \%$ of the patients felt that time went by faster after the interventions in both rhythms. However, the pace was a decisive factor in the kind of emotional experience that the patients had.
\end{abstract}

\section{KEY WORDS}

Complementary therapies.

Renal dialysis.

Music therapy.

\section{RESUMEN}

Someterse a la Hemodiálisis cuatro horas por día, tres veces por semana, puede configurarse en una experiencia cargada de tedio, además de causar incomodidad durante su realización. Es común que los pacientes relaten que el tiempo parece arrastrarse 0 durar más. El objetivo de este estudio fue conocer la influencia de dos diferentes ritmos musicales en los estados subjetivos y en la percepción del tiempo sensorial de pacientes adultos sometidos a la hemodiálisis, una vez que la literatura sobre esa temática es escasa. El estudio fue realizado en un hospital privado, con 43 pacientes en hemodiálisis, que se sometieron a dos sesiones de improvisación musical en un teclado, en las cuales los estados subjetivos y la percepción temporal fueron evaluadosantesy después de la intervención. Más de $80 \%$ de los pacientes sintió el tiempo pasar más rápido después de las intervenciones en ambos ritmos. Sin embargo, el ritmo influenció el tipo de experiencia emocional que los pacientes presentaron.

\section{DESCRIPTORES}

Terapias complementarias.

Diálisis renal.

Musicoterapia.

${ }^{1}$ Graduando em Enfermagem da Escola de Enfermagem da Universidade de São Paulo. Bolsista PIBIC-CNPq. São Paulo, SP, Brasil. bechertcaminha@hotmail.com ${ }^{2}$ Professora Titular do Departamento de Enfermagem Médico-Cirúrgico da Escola de Enfermagem da Universidade de São Paulo. Coordenadora do Grupo de Estudos de Práticas Complementares de Saúde do CNPq. São Paulo, SP, Brasil. juliaps@usp.com ${ }^{3}$ Doutora em Enfermagem. Pós-doutorada pela Universidade de Strabourg. Assessora de Pesquisa Científica do Hospital Samaritano. Vice-coordenadora do Grupo de Estudo de Práticas Complementares de Saúde do CNPq. São Paulo, SP, Brasil. eliseth.leao@samaritano.org.br 


\section{INTRODUÇÃO}

A doença renal crônica tem elevada morbidade e mortalidade e cresce em proporções endêmicas a cada ano no Brasil e no mundo ${ }^{(1)}$, com proeminente comprometimento da qualidade de vida, razão pela qual se torna alvo de interesse da Enfermagem a investigação de novas formas de cuidado que possam melhorar a assistência prestada a esses pacientes. Dentre os diversos fatores que acabam por comprometer a qualidade de vida dos pacientes renais crônicos, destaca-se a necessária realização das sessões constantes de hemodiálise ${ }^{(2)}$.

A hemodiálise é o processo de filtragem e depuração de substâncias indesejáveis do sangue, sendo realizada, em média, três vezes por semana com duração de quatro horas a cada sessão, ou seja, o paciente passa muitas horas de sua vida ligado à máquina dialisadora e, normalmente, refere essa experiência como tediosa, na qual o tempo parece se arrastar, além do desconforto dos eventos adversos, dentre eles, a dor ${ }^{(3)}$, que às vezes 0 acometem durante a sessão dialítica.

A música tem aplicação clínica variada e há vasta literatura sobre sua utilização como recurso terapêutico na prática da Enfermagem, como por exemplo, no controle da dor ${ }^{(4)}$, sendo utilizada também por outros profissionais ${ }^{(5-6)}$. Todavia, estudos sobre sua utilização na assistência aos pacientes submetidos à hemodiálise são bastante restritos. Pesquisa bibliográfica realizada na base de dados Pubmed relacionando especificamente música ou musicoterapia e hemodiálise resultou em seis artigos, três deles de origem oriental. 0 estudo de caso chinês apresenta os resultados de um programa conduzido por enfermeiros com musicoterapia, aromaterapia e massagem como forma de minimizar o senso de desesperança e estresse apresentado por um paciente em hemodiálise, o que favoreceu a expressão de sentimentos e uma atitude mais positiva frente à doença ${ }^{(7)}$. Estudo coreano sobre a influência da música sobre a depressão e ansiedade de 36 pacientes em hemodiálise também apontou uma utilização como intervenção de Enfermagem efetiva, uma vez que os pacientes do grupo experimental apresentaram menores índices em relação ao grupo controle ${ }^{(8)}$. Uma referência não apresentava o resumo publicado e três outras referiam-se à hemodiálise, mas o termo música foi utilizado em outro contexto que não terapêutico, o que reforçou a necessidade de realização deste estudo.

Os teóricos concordam que os estados de ânimo são gerais e menos intensos, enquanto as emoções são relativamente específicas e mais intensas. Um evento para um indivíduo (como a música) pode determinar se a reação é uma emoção ou um estado de ânimo. Se o evento for de grande significância poderá acarretar uma reação mais forte que caracteriza a emoção. Por outro lado, se o evento for menos intenso caracterizam-se alterações somente nos estado de ânimo ${ }^{(9)}$. Todavia, ambos constituem estados subjetivos, que são afetados pela música de modo geral(10). Os estados subjetivos, portanto, podem ser compreendidos como fatos da consciência caracterizados por diversas percepções e, em grande parte, por emoções, sentimentos e humor. Denomina-se estados porque dura sempre certo tempo, ainda que esse tempo seja curto, médio ou longo e subjetivos (internos) por se referir à parte debaixo do percepto da pele do indivíduo. 0 percepto diz respeito ao tipo de conteúdo perceptivo da consciência(11), o que inclui, dentre outros, a percepção temporal, as emoções e os estados de ânimo, os quais podem ser modulados de forma positiva pela música no ambiente hospitalar ${ }^{(4)}$. Por seu caráter não verbalizável atravessa redes defensivas que a consciência e a linguagem cristalizada opõem à sua ação e toca em pontos de ligação efetivos do mental e do corporal, do intelectual e do afetivo ${ }^{(12)}$.

A música é constituída por som. A onda sonora é um sinal oscilante e recorrente, que retorna por períodos (repetindo certos padrões de tempo), ou seja, obedece a um pulso, razão pela qual se pode pensar em uma correspondência entre as escalas sonoras e as escalas corporais com as quais medimos o tempo ${ }^{(12)}$. Os compassos musicais facilitam a execução musical ao definir a unidade de tempo, o pulso e o ritmo da composição ou de partes dela. Ritmo vem do grego Rhytmos e designa aquilo que flui, que se move, movimento regulado.

0 complexo corpo/mente é um medidor de freqüências (que percebemos como recortes de tempo) e toda a nossa experiência sonora e com a música passa por certos padrões de pulsação somáticos e psíquicos, com os quais jogamos ao ler o tempo e o som. Os sons, portanto, nos remetem no seu vai-e-vem ao tempo sucessivo e linear, mas também a um outro tempo, virtual, espiral, não cronológico, que sugere um contraponto entre o tempo da consciência e o não-tempo do inconsciente; além do que o ritmo está na base de todas as nossa percepções ${ }^{(12)}$.

0 aspecto rítmico, portanto, relacionado à música, e 0 fato dela se desenvolver em uma matriz temporal nos levou a questionar sobre a possibilidade de alterar os estados subjetivos, incluindo a percepção do tempo dos pacientes em hemodiálise, com vistas a tornar a experiência menos enfadonha e mais rápida para eles, através de ritmos musicais, a fim de ampliar a compreensão da música como intervenção de Enfermagem em nosso meio.

\section{OBJETIVO}

Conhecer a influência de dois diferentes ritmos musicais (valsa e marcha) nos estados subjetivos de pacientes adultos submetidos a sessões de hemodiálise. 


\section{MÉTODO}

Trata-se de um ensaio clínico não controlado realizado em um serviço de hemodiálise de um hospital geral, de médio porte, da cidade de São Paulo, em julho de 2007.

A amostra por conveniência foi constituída por 43 pacientes que atenderam os seguintes critérios de inclusão: adultos submetidos à hemodiálise, com diagnóstico de insuficiência renal crônica, sem déficit auditivo referido, sem diagnósticos médicos associados que implicassem em alteração cognitiva, com comunicação oral preservada e que aceitaram participar da pesquisa e assinaram o Termo de Consentimento Livre e Esclarecido, em conformidade com a legislação brasileira para realização de estudos com seres humanos (Resolução CNS 196/96), após tomarem conhecimento sobre o objetivo da pesquisa.

0 estudo foi submetido à análise do Comitê de Ética em Pesquisa da instituição e foi aprovado sob no 03/07 em reunião ordinária realizada em 27/04/ 2007.

A técnica de improviso foi executada por um dos pesquisadores, que é também pianista, nos dois ritmos propostos: marcha e valsa. A marcha constitui um ritmo binário, ou seja, sua célula rítmica formada por dois tempos (12). 0 pulso é forte - fraco, ou seja, o primeiro tempo do compasso é forte e o segundo é fraco. Já a valsa constitui um ritmo ternário, ou seja, é formada por três tempos (12-3). 0 pulso é forte - fraco - fraco, ou seja, o primeiro tempo do compasso é forte, o segundo é fraco e o terceiro também é fraco. Os improvisos tiveram duração de 20 minutos para cada ritmo em duas sessões distintas, conforme Quadro 1, compostos por músicas e sons instrumentais (temas não populares para evitar associações pessoais e minimizar a evocação de memórias) executados em um teclado Yamaha PSR 620.

Quadro 1 - Distribuição das turmas de hemodiálise e ritmo musical utilizado - São Paulo - 2007

\begin{tabular}{|c|c|c|}
\hline Turmas & $\begin{array}{c}\mathbf{1}^{\text {a }} \text { semana } \\
\text { intervenção }\end{array}$ & $\begin{array}{c}\mathbf{2}^{\mathbf{a}} \text { semana } \\
\text { intervenção }\end{array}$ \\
\hline $2^{\mathrm{a}}$ manhã & Marcha & Valsa \\
\hline $4^{\mathrm{a}}$ manha & Valsa & Marcha \\
\hline $2^{\mathrm{a}}$ tarde & Marcha & Valsa \\
\hline $4^{\mathrm{a}}$ tarde & Valsa & Marcha \\
\hline $3^{\mathrm{a}}$ manhã & Marcha & Valsa \\
\hline $5^{\mathrm{a}}$ manhã & Valsa & Marcha \\
\hline $3^{\mathrm{a}}$ tarde & Marcha & Valsa \\
\hline $5^{\mathrm{a}}$ tarde & Valsa & Marcha \\
\hline
\end{tabular}

Os pacientes foram divididos em 4 turmas a saber, sendo a primeira turma na 2a feira e 4a feira pela manhã; segunda turma na 2 a feira à tarde e 4 a feira à tarde; terceira turma na 3a feira de manhã e 5 a feira de manhã; quarta turma na 3 a feira à tarde e 5 a feira à tarde.
Nos dias correspondentes à intervenção musical os estados subjetivos foram avaliados imediatamente antes e imediatamente após cada sessão musical, utilizando instrumento adotado em estudo sobre o impacto da música nos estados de ânimo de pacientes hospitalizados ${ }^{(13)}$. A percepção temporal foi verificada por uma questão específica para que o paciente indicasse se o tempo passou de forma igual, se foi mais rápido ou se a sessão de hemodiálise lhe pareceu durar mais.

Os dados foram submetidos à análise estatística analítica (Programas NCSS e STATPLUS). 0 nível de significância adotado foi de $5 \%$. As estatísticas com p descritivo $<=0,05$ foram consideradas significantes. Empregou-se como técnica não-paramétrica o teste de Postos com Sinais de Wilcoxon, ajustado pelos empates para comparar a magnitude da diferença entre cada par. No presente estudo, cada par foi considerado como sendo o mesmo indivíduo, tanto no pré-pós, como em ritmos diferentes (marcha, valsa). Empregaram-se também para análise exploratória os gráficos de comparações múltiplas de grupos, incluind o o gráfico de barras com o error bar para mediana (intervalo de confiança de 25-75 percentis) e com o dot plot (todos os pacientes) e os histogramas comparativos.

\section{RESULTADOS E DISCUSSÃO}

A média de idade do grupo estudado foi de 63 anos, com variação de 23 a 93 anos. Pode-se constatar o predomínio do sexo M asculino $(62,8 \%)$ em relação ao sexo Feminino (37,2\%). Dos 43 pacientes estudados, 30 (70\%) eram idosos (acima de 60 anos).

Com relação ao tempo de diálise as quais os pacientes do estudo estavam submetidos, constatou-se que $65 \%$ dos pacientes apresentavam menos de 5 anos de diálise. A média de tempo foi de 4,5 anos, com variação de 10 mesesa 12,3 anos.

A amostra de idosos demonstrou que 21 pacientes (70\%) estavam dialisando há menos de 5 anos, 15 dos pacientes (35\%) vinham sendo submetidos à diálise há, no mínimo, 5 anos.

Para calcularmos a magnitude dessa experiência para os pacientes é só estimarmos que: ser submetido à Hemodiálise por apenas 1 ano (média de 3 vezes por semana com duração de 4 horas cada dia) nos leva à conclusão de que, o indivíduo fica ligado 625 horas, 156 dias de sua vida à máquina dialítica, ou seja, $43 \%$ do período avaliado que representa, portanto, quase metade do ano. Esse dado reforça que a submissão ao tratamento produz sentimentos que são percebidos como fator de impacto na qualidade de vida ${ }^{(14)}$.

Quanto à preferência musical, verificamos uma grande diversidade entre os pacientes: 10 dos 43 pacientes (25\%) afirmaram ser ecléticos e 0 restante variou muito em diversos estilos musicais. Apenas um paciente $(2 \%)$ relatou não ouvir música, o que demonstra, mais uma vez, o cará- 
ter universal e a grande aceitação dessa prática complementar de saúde.

M uitos acreditam que a música serve apenas para entretenimento, outros a utilizam em diversos ambientes e atividades diárias. Conscientes ou não, as pessoas têm uma predileção pessoal e intransferível. Entretanto, ao que parece, os dados encontrados sugerem que a preferência musical não interferiu nos resultados obtidos, uma vez que o ritmo utilizado, na sua maioria não condizia com a preferência indicada. Alguns estudos têm demonstrado essa não interferência da preferência musical nos resultados mensurados ${ }^{(4)}$.

Com relação à percepção temporal, a Tabela 1 e a Figura 1 demonstram que, para a maioria, a percepção foi de que 0 tempo passou mais rápido e que o tipo de ritmo não influenciou na resposta da percepção temporal dos pacientes.

Tabela 1 - Percepção temporal dos pacientes após as duas sessões musicais - São Paulo - 2007

\begin{tabular}{|c|c|c|c|c|c|c|c|c|}
\hline \multirow{3}{*}{$\begin{array}{l}\text { Percepção } \\
\text { Temporal } \\
\text { após } \\
\text { Intervenção }\end{array}$} & \multicolumn{4}{|c|}{$\begin{array}{l}\text { Ritmo Binário } \\
\text { (Marcha) }\end{array}$} & \multicolumn{4}{|c|}{$\begin{array}{l}\text { Ritmo Ternário } \\
\text { (Valsa) }\end{array}$} \\
\hline & \multicolumn{2}{|c|}{$1^{\circ} \mathrm{s}$} & \multicolumn{2}{|c|}{$2^{\circ} \mathrm{S}$} & \multicolumn{2}{|c|}{$1^{\circ} \mathrm{s}$} & \multicolumn{2}{|c|}{$2^{\circ} \mathrm{s}$} \\
\hline & $\mathrm{f}$ & $\%$ & $f$ & $\%$ & $\mathrm{f}$ & $\%$ & $\mathrm{f}$ & $\%$ \\
\hline $\begin{array}{l}\text { 1. Mais } \\
\text { Rápido }\end{array}$ & 32 & 80 & 34 & 81 & 33 & 85 & 35 & 83 \\
\hline $\begin{array}{l}\text { 3. Mais } \\
\text { Devagar }\end{array}$ & --- & & --- & & --- & & 1 & 2 \\
\hline 2. Igual & 8 & 20 & 8 & 19 & 6 & 15 & 6 & 15 \\
\hline Total & 40 * & & $42 *$ & & $39 *$ & & $42 *$ & \\
\hline
\end{tabular}

* O total de pacientes não atingiu 43 porque houve ausência em algumas das sessões.

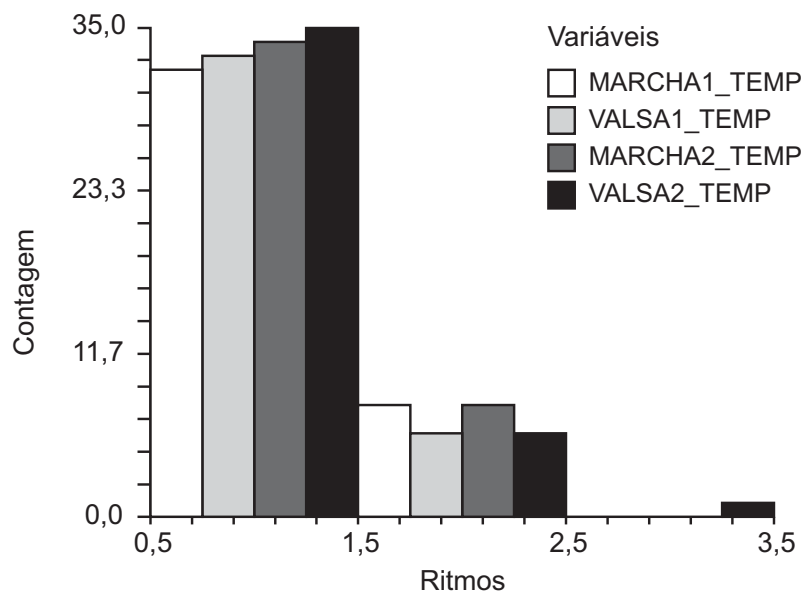

Figura 1 - Percepção temporal dos pacientes após duas sessões musicais - São Paulo - 2007

A música nos tira de nossos hábitos mentais congelados e faz nossas mentes se movimentarem como habitualmente não são capazes. Quando somos envolvidos por música bem escrita, temos uma compreensão que supera a da nossa existência mundana e, em geral, está além da lembrança. Quando o som cessa, voltamos para nossas cadeiras de rodas men- tais(15). Tal idéia pode justificar a sensação de que o tempo passou mais rápido para os pesquisados.

Toda percepção de tempo é percepção de mudança. 0 tempo não é uma dimensão fria, de pura constatação; permeia-se de desejos e afetos. A duração é expectativa e é tédio. 0 fator emocional afeta os ponteiros subjetivos ${ }^{(16)}$. Alguns autores, por exemplo, persuadiram seus sujeitos que uma espera seria seguida de um evento agradável ou de um evento desagradável ou, ainda, de uma experiência neutra. O grupo com expectativa positiva viu o tempo passar muito mais devagar do que os outros. Os grupos de expectativa neutra e negativa tenderam a subestimar o intervalo ${ }^{(17)}$.

A partir dessas questões, observamos que a maioria dos pacientes submetidos à Hemodiálise não esperava melhoras ou sensações positivas. M as como a música não é um procedimento invasivo e tem uma aceitação universal grande, podemos inferir que aceitaram ouví-la sem problemas, porém sem estabelecer de antemão perspectivas, o que remonta colocá-los na perspectiva de um grupo neutro. Observamos que a maioria se divertiu, gostou da execução, cantou, bateu o pé junto com o ritmo. Ao final, a maioria dizia: - AAAAAAAH...Já terminou ? demonstrando que a execução era, no mínimo, interessante para eles.

Independentemente do ritmo utilizado, observou-se que a maioria apresentou uma melhora nos estados de ânimo, o que corrobora a influência da música no bemestar das pessoas no ambiente hospitalar ${ }^{(8,15,18)}$.

Tabela 2 - Percepção sensorial de bem estar dos pacientes após as duas sessões musicais - São Paulo - 2007

\begin{tabular}{|c|c|c|c|c|c|c|c|c|}
\hline \multirow{3}{*}{$\begin{array}{l}\text { Percepção } \\
\text { sensorial de } \\
\text { bem estar } \\
\text { após } \\
\text { intervenção }\end{array}$} & \multicolumn{4}{|c|}{$\begin{array}{l}\text { Ritmo Binário } \\
\text { (Marcha) }\end{array}$} & \multicolumn{4}{|c|}{$\begin{array}{l}\text { Ritmo Ternário } \\
\text { (Valsa) }\end{array}$} \\
\hline & \multicolumn{2}{|c|}{$1^{\circ} \mathrm{s}$} & \multicolumn{2}{|c|}{$2^{\circ} \mathrm{s}$} & \multicolumn{2}{|c|}{$1^{\circ} \mathrm{s}$} & \multicolumn{2}{|c|}{$2^{\circ} \mathrm{s}$} \\
\hline & $\mathrm{f}$ & $\%$ & $\mathrm{f}$ & $\%$ & $\mathrm{f}$ & $\%$ & $\mathrm{f}$ & $\%$ \\
\hline $\begin{array}{l}\text { 1. Mais } \\
\text { Rápido }\end{array}$ & 25 & 62,5 & 29 & 69 & 33 & 85 & 33 & 78,5 \\
\hline $\begin{array}{l}\text { 3. Mais } \\
\text { Devagar }\end{array}$ & 1 & 2,5 & --- & & --- & & 2 & 4,5 \\
\hline 2. Igual & 14 & 35 & 13 & 31 & 6 & 15 & 7 & 17 \\
\hline Total & $40 *$ & & $42 *$ & & $39 *$ & & $42 *$ & \\
\hline
\end{tabular}

* $O$ total de pacientes não atingiu 43 porque houve ausência em algumas das sessões.

Uma interferência importante ocorreu na pesquisa: os Jogos Pan-Americanos. Os jogos eram televisionados; então, alguns dias ao desligar a televisão, alguns pacientes, principalmente os mais jovens, ficavam insatisfeitos. Até pela liberdade que eles sentiam ter com o pesquisador, diziam: Ahhhh, só abaixa o VOLUM E, toca teclado, mas deixa a TV ligada sem volume... Daí era explicado sobre a importância da concentração e da imagem da TV como interferência na pesquisa. 0 paciente que relatou sobre o tempo ter passado mais devagar após a intervenção e dois pacientes que relataram terem se sentido pior após a intervenção, afirmaram o desgosto de não poder ter acompanhado 
os jogos Pan-Americanos que estava sendo televisionado no momento da Intervenção. Por isso se sentiram dessa forma. Apenas um paciente relatou ter se sentido pior por outro motivo: o ritmo marcha para essa pessoa apenas era muito chato e barulhento o que lhe tirava a tranqüilidade.

Tabela 3 - Estados subjetivos presentes antes e após as sessões musicais - São Paulo - 2007

\begin{tabular}{lcccc}
\hline \multirow{2}{*}{$\begin{array}{l}\text { Estados } \\
\text { Subjetivos }\end{array}$} & \multicolumn{2}{c}{ Sessão Marcha } & \multicolumn{2}{c}{ Sessão Valsa } \\
\cline { 2 - 5 } Tranqüilidade & 45 & 45 & 48 & 50 \\
Alegria & 7 & 9 & 5 & 7 \\
Calma & 4 & 8 & 5 & 7 \\
Paz & --- & 8 & --- & 12 \\
Distração & --- & 2 & --- & 3 \\
Animação & --- & 2 & --- & 2 \\
Preocupação & 5 & 1 & 4 & --- \\
Conformação & 4 & --- & 4 & --- \\
Chateação & 4 & --- & 4 & --- \\
Ansiedade & 2 & 2 & 3 & --- \\
Revolta & 2 & --- & 2 & --- \\
Raiva & --- & 2 & --- & --- \\
Normal & 9 & 3 & 6 & --- \\
\hline Total & 82 & 82 & 81 & 81 \\
\hline
\end{tabular}

Observamos que, após a execução da Marcha, houve diferenças nos sentimentos, aumentando as sensações de calma, alegria, distração, animação, paz e diminuindo sensações de chateação, preocupação, revolta e conformação, denotando a importância desse tipo de intervenção para esses pacientes quando ligados à máquina de Diálise.

Da mesma maneira, observamos que após a execução da Valsa, houve diferenças nos sentimentos, aumentando, mais do que na Marcha, a sensação de tranqüilidade, distração, paz e diminuindo mais, quando comparados à M archa, sensações de ansiedade. 0 que se observa é que, embora o tipo de ritmo pareça não interferir na percepção temporal, ele parece ter sido um fator determinante para o tipo de experiência emocional que os pacientes apresentaram, revelando significância estatística conforme demonstrado na Tabela 4.

As estruturas musicais, as quais o ritmo integra, apresentam propostas diferentes, o que temos visto ser utilizado com freqüência nas trilhas sonoras de filmes, por exemplo.

Para compreendermos as experiências sugeridas por diversos ritmos, podemos analisar a sua gênese de composição e os fatores culturais envolvidos. A M archa, tal qual conhecemos hoje, é bem diferente do seu gênero militar, mas tanto a marcha tradicional como o frevo tiveram seus primeiros passos guiados pelas bandas de música das corporações militares do século XX. Já a marcha carnavalesca, de ritmo festivo, só guarda semelhança com a marcha militar no compasso binário. Esse ritmo considerado vivo e com caráter de enfrentamento, típico da marcha militar é bem diferente da Valsa, palavra com origem no alemão Walzen, que significa deslizar.

Tabela 4 - Teste de postos com sinais de Wilcoxon para os estados subjetivos apresentados pelos pacientes nas sessões musicais - São Paulo - 2007

\begin{tabular}{lcccc}
\hline Test Statistics* & $\begin{array}{l}\text { Marcha 1_Pós I } \\
\text { Marcha 1_Pré }\end{array}$ & $\begin{array}{l}\text { Valsa 1_Pós I } \\
\text { Valsa 1_Pré }\end{array}$ & $\begin{array}{l}\text { Marcha 2_Pós I } \\
\text { Marcha 2_Pré }\end{array}$ & $\begin{array}{l}\text { Valsa 2_Pós I } \\
\text { Valsa 2_Pré }\end{array}$ \\
\hline$Z$ & $-2,874$ & $-3,217$ & $-2,183$ & $-2,762$ \\
$\begin{array}{l}\text { Significância } \\
\text { Bicaudal }\end{array}$ & 0,004 & 0,001 & 0,029 & 0,006 \\
\hline
\end{tabular}

* Wilcoxon Signed Ranks Test

Marcada por seu compasso ternário, ao longo da segunda metade do século XIX, continuaria tendo grande aceitação e seria, nas palavras de um pesquisador, um dos únicos espaços públicos de aproximação que a época oferecia a namorados e amantes ${ }^{(18)}$, o que revela, portanto, uma proposta mais romântica e de devaneio e com subsequentes estados de ânimos mais compatíveis para cada ritmo em associação a outros elementos musicais. Essas características podem ajudar a entender o estímulo que um determinado ritmo pode causar sobre um determinado sentimento em detrimento de outro.
0 cuidar em Enfermagem pode ser entendido como um conjunto de ações e comportamentos realizados no sentido de favorecer, manter ou melhorar a condição humana no processo de viver ou morrer. Neste sentido, o processo de cuidar é um processo interativo, de desenvolvimento, de crescimento, que se dá de forma contínua ou em um determinado momento, mas quetem o poder de conduzir à transformação. Ao que parece, a música se confirma como um valioso recurso nesse sentido. Despertar nos pacientes esses tipos de sentimentos faz parte da qualificação dos cuidados, sendo possível buscar esferas mais saudáveis, tanto físicas, quanto mentais. 


\section{CONSIDERAÇÕES FINAIS}

De acordo com o objetivo proposto, pudemos verificar que o tipo de ritmo parece não ter influenciado na resposta da percepção temporal dos pacientes. Ambos os ritmos influenciaram intensamente essa percepção, o que levou os pacientes à sensação de que o tempo passou mais rápido. No entanto, a Valsa foi mais aceita e decisiva na percepção de bem-estar, estimulando inclusive, mais do que a Marcha, sentimentos de tranqüilidade, paz e distração, além de diminuir a ansiedade.

Com menor ênfase do que a Valsa, a M archa também teve ação na percepção de bem estar dos pacientes e estimulou mais fortemente sentimentos de alegria, distração e animação. Considerando o caráter mais festivo desse ritmo, era esperado esse tipo de comportamento.

Um aspecto interessante a ser observado é que não se pode reduzir a experiência vivenciada pelos pacientes somente aos ritmos M archa e Valsa. Devemos considerar também o Campo Energético Humano do pesquisador que esteve com os pacientes todas as manhãs e tardes durante 0 mês de Julho, sorrindo, conversando antes e depois da intervenção, criando vínculos e mais ainda: fazendo música ao vivo para eles, o que é muito diferente de música ambiente ou qualquer outra modalidade de audição musical passiva. A interação humana faz parte e é uma variável que, embora difícil de mensurar e medir, está presente na pesquisa desenvolvida no ambiente clínico (já que o experimento não foi conduzido em laboratório).

0 estudo apresenta algumas limitações: a impossibilidade de isolar na intervenção realizada, somente o ritmo dos demais elementos sonoro-musicais inerentes à utilização de um instrumento harmônico. Talvez estudos desenhados unicamente com instrumentos de percussão possam revelar maior acurácia para esse tipo de análise, além da inclusão do ritmo quaternário. Vale ressaltar, portanto, que os resultados deste trabalho reafirmam que apenas 0 ritmo, melodia improvisada e harmonia desconhecida, juntamente com o timbre de piano trouxeram à tona as mesmas propriedades conhecidas há anos, de que a música traz benefícios dos mais diversos, que ultrapassam as barreiras do físico e incidem sobre o mental, o cognitivo e o social. Além disso, enquanto não a compreendermos de forma

\section{REFERÊNCIAS}

1. Sesso R. Epidemiologia da doença renal crônica no Brasil e sua prevenção [texto na Internet]. São Paulo: CVE; 2006. [citado 2008 ago. 8]. Disponível em: http:// www.cve.saude.sp.gov.br/ htm/cronicas/irc_prof.htm.

2. Castro M, Caiuby AVS, Draibe SA, Canziani MEF. Qualidade de vida de pacientes com insuficiência renal crônica em hemodiálise avaliada através do instrumento genérico SF-36. Rev Assoc Med Bras. 2003;49(3):245-9. satisfatória para que possamos prescrevê-la com segurança, eficácia e consciência, novos estudos devem ser desenvolvidos pelos profissionais de saúde.

À guisa de considerações finais, a seguir, são relatados aspectos que não foram objetivados nesse estudo, mas que foram significativos para o autor que desenvolveu a atividade musical durante a realização da pesquisa e por considerarmos também, que podem suscitar novos alvos de investigação.

A aceitação por parte dos pacientes foi visível e a sensação deles durante a execução foi um grande elemento motivador. Foi gostoso o relacionamento, aquela aceitação por parte de todos e o mês de julho realmente voou não só para os pacientes.

Cada dia era mais motivante e era clara a reciprocidade por parte dos pacientes. Quando eles chegavam, já vinham abraçar, conversar, elogiar, perguntar sobre a possibilidade de aulas particulares, além de pedir inúmeras músicas que eles gostavam ao término da execução.

Alguns pacientes, a despeito do ritmo, choravam ao término da execução, demonstrando que, mesmo improvisando melodias diferenciadas e desconhecidas, elas eram capazes de estimular a imaginação e trazer memórias passadas.

Os pacientes cegos pareciam ser mais sensíveis à execução do que os que tinham a visão preservada. Apenas uma paciente estava sedada o tempo inteiro e não foi considerada para a coleta de dados. Todavia, foi solicitado à mãe que, durante a execução, observasse as expressões e reações da filha. Ela, que permaneceu ao seu lado durante todas as execuções, relatou que todas as vezes sua filha acalmou, demonstrou expressões suaves de face, ficando menos agitada, principalmente, durante a Valsa, o que merece ser investigado oportunamente com rigor metodológico.

A aceitação por parte dos pacientes e a necessidade dessa intervenção também foram percebidas como parte do cuidado não farmacológico e como uma prática complementar de saúde, pois muitos pediam pra não se esquecer deles e voltar outras vezes porque a música traz muita alegria e 0 ambiente da Diálise é muito triste, em silêncio, além de cronologicamente constante. Quatro horas... Esses aspectos, portanto, também apontam para a necessidade dessa Prática Complementar de Saúde na vida dessas pessoas.

3. Antoniazzi AL, Bigal ME, Bordini CA, Speciali JG. Cefaléia relacionada à hemodiálise: análise dos possíveis fatores desencadeantes e do tratamento empregado. Arq Neuropsiquiatr. 2002;60 (3A):614-8.

4. Leão ER, Silva MJP. A música como intervenção de enfermagem no controle da dor. In: Chaves LD, Leão ER. Dor 50 sinal vital: reflexões e intervenções de enfermagem. $2^{2}$ ed. São Paulo: Martinari; 2007. p. 581-606. 
5. Hatem TP, Lira PIC, M attos SS. Efeito terapêutico da música em crianças em pós operatório de cirurgia cardíaca. J Pedriatr. 2006;82(3):186-92.

6. Barcellos LR, organizador. Vozes das musicoterapia brasileira. São Paulo: Apontamentos; 2007.

7. Yeh SC, Yeh HF. Using complementary therapy with a hemodialysis patient with colon cancer and a sense of hopelessness. $\mathrm{Hu} \mathrm{Li} \mathrm{Za}$ Zhi. 2007;54(5):93-8

8. Kim KB, Lee MH, Sok SR. The effect of music therapy on anxiety and depression in patients undergoing hemodialysis. Taehan Kanho Hakhoe Chi. 2006;36(2):321-9.

9. Mori P, Deutsch S. Alterando estados de ânimo nas aulas de ginástica rítmica com e sem a utilização de música. Motriz. 2005;11(3):161-6.

10. Bueno VF, M acedo EC. Julgamento de estados emocionais em faces esquemática por meio da música por crianças. Psicol Teor Prat. 2004;6(2):27-36.

11. Engelmann A. Da conceituação de estado subjetivo até a proposição dos escalões de percepto. Psicol Reflex Crit. 2002;15(2):393-405.

12. Wisnik JM. O som e o sentido: outra história das músicas. São Paulo: Companhia das Letras; 1999.
13. Leão $E R$, Aquino CR, Bussoti EA, Ribeiro EFF. Uma canção no cuidar: a música humanizando a assistência. In: Anais do 9o Encontro de Enfermagem e Tecnologia (ENFTEC); 2004; São Paulo, BR[CD-ROM ]. São Paulo: Hospital Nove de Julho; 2004.

14. Lima AFC. Significado da hemodiálise para o paciente renal crônico: a busca por uma melhor qualidade de vida [dissertação]. São Paulo: Escola de Enfermagem, Universidade de São Paulo; 2000.

15. Jourdain R. Música, cérebro e êxtase. Rio de Janeiro: Objetiva; 1998.

16. Poynter D. Judging the duration of time intervals: a process of remembering segments of experience. In: Levin I, Zakay D. Time and human cognition: a life-span perspective. Amsterdam: Elsevier; 1989. p. 305-21.

17. Edmonds EM, Cahhon D, Ridges BA. The estimation of time as a function of positive, neutral and negative expectancies. Bull Psychon Soc. 1981;17:259-60.

18. Tinhorão JR. Tudo sobre valsa [texto na Internet]. [citado 2008 mar. 8]. Disponível em: http://brasiliavirtual.info/tudo-sobre/ valsa 